\title{
Comment
}

Neuroepidemiology 2009;33:342-343

DOI: $10.1159 / 000254570$

\section{Tuberous Sclerosis: Epidemiology, Genetics and Progress towards Treatment}

Patrick J. Morrison

Belfast City Hospital Trust, Belfast, UK

\section{Introduction}

Genetic disorders are interesting from an epidemiological ascertainment point of view. Tuberous sclerosis complex (TSC) was first described by Bournville in 1880 [1]. More recently, Roach et al. [2] defined the clinical criteria. The name tuberous sclerosis stems from tubers seen in the cerebral cortex (best shown by brain $\mathrm{MRI}$ ), and periventricular calcification is also characteristic. Epilepsy occurs in $60 \%$ of patients and learning disability in around $40 \%$. It is a disorder with challenges of the highest order in both management and treatment.

\section{Presentation of TSC}

Clinical features are variable, and include facial angiofibromas, epilepsy and skin hypopigmentation, with periungual fibromas and dental enamel pits. More serious complications include cardiac rhabdomyomas in early age, which may cause cardiac arrhythmias. Renal angiomyolipomas (65\%) present with advancing age, and lead to renal cell carcinoma in around $3 \%$ of cases. Subacute giant cell astrocytomas (SEGA) occur in $1 \%$ of patients, often causing obstructive hydrocephalus. Age at onset varies, and so does the presentation of symptoms: infantile spasms, childhood skin disorders, hypopigmented macules, adolescent learning disability or adult renal disease (in increasing age of presentation). Only $4 \%$ of cases present with epilepsy in adulthood, and there may be no features or only one solitary feature such as periungual fibromas.

Genetic testing is available for the 2 causal genes TSC1 (hamartin, around $45 \%$ of cases) and TSC2 (tuberin, around $55 \%$ of cases). Although time-consuming (this may take around 10-14 months in some centres) and expensive, in some situations this is particularly useful, such as when there is no family history to allow diagnosis of familial cases, or in cases where there is a family history in order to clarify risks to siblings and children as non-penetrance is high, or in cases of prenatal diagnosis.

Screening for renal angiomyolipomas and brain CT or MRI to check for cortical tubers and SEGA is recommended, and helps manage complications early. At-risk relatives should have a detailed clinical examination and genetic testing or brain $\mathrm{CT}$ and ultrasound of the renal tracts. Few cases are thought to be due to causes other than the TSC1 and TSC2 genes.
How Common Is TSC?

Studies over the last 4 decades have relied on epidemiological assessment and clinical examination of families. More recently, genetic testing has become available to confirm cases. Autosomal dominant genetic disorders, however, are prone to variable penetrance and expression - some patients may carry the gene and have either no obvious or no severe features that would lead to diagnosis. Both genes arise as new mutations in $60-70 \%$ of cases. Population studies have attempted to estimate the prevalence of TSC: in 1989, Sampson et al. [3] reported a prevalence of 1 in 27,000 in the west of Scotland, and, in 1996, Webb reported a prevalence of 1 in 26,500 in the south of England [4]. Accuracy and total ascertainment vary, with most studies being incomplete. In 1999, we commenced a prevalence study of TSC in the entire Northern Ireland region (population 1.7 million), and several methods of ascertainment were employed, including case note analysis from multiple sources, which involved trawling through medical genetic records from one of the first ever surveys in 1956, which was also later repeated in 1968, as it is always good to do a further survey to help with maximising multiple ascertainment sources and the accuracy of the prevalence rate [5]. Patient identification requests were made to all relevant medical specialties, including paediatrics, dermatology, neurology and psychiatry in particular. Cases were personally confirmed using defined diagnostic criteria, and also later on with genetic testing. A prevalence of 1 in 25,000 was identified, and is considered to be one of the most accurate in the world for a Caucasian population [6].

\section{Possibilities for Treatment}

No studies in large Eastern populations have so far been described, so the article in this issue by Hong et al. [7] on the Taiwanese population is groundbreaking in several respects. First, it is the best-documented study in a non-Caucasian population to date, and confirms that TSC occurs worldwide. Second, the prevalence of 1 in 95,136 can only be a minimum prevalence, as further cases will undoubtedly be described when molecular genetic testing of affected cases and further investigation of family members confirms the true extent of asymptomatic cases, and also tells us the proportion of TSC1 and TSC2 mutations. Third (and most importantly), the study is interesting in that it uses a health insurance database to estimate the prevalence in an entire population of whom the authors estimate $95 \%$ are enrolled. This lower prevalence compared to Western countries may affect different founder effects in mutation transmission through different populations over time, and family planning or disease-modifying genes may also contribute to the lower prevalence. There is clearly potential here for therapeutic and molecular studies and improving the ascertainment from further sources of cases, along with DNA analysis. Identification of modifying genes that may reduce the effects of this tragic disorder would be a major advance. Hong et al. [7] are to be congratulated on their study and its design, and the next phase may include molecular genetic analysis of their families and

\section{KARGER}

Fax +41613061234 E-Mail karger@karger.ch www.karger.com
(2) 2009 S. Karger AG, Basel

0251-5350/09/0334-0342\$26.00/0 
the eventual identification of potential treatments. Already, rapamycin has been shown to have some effect on shrinkage of tumours in this disorder [8], and progress in the identification and recognition of cases may allow therapies for this devastating disorder to be initiated through molecular epidemiology studies.

\section{References}

1 Bourneville D: Sclérose tubéreuse des circonvolution cérébrales: idiotie et épilepsie hemiplégique. Arch Neurol 1880;1:81-91.

$\checkmark 2$ Roach ES, Gomez MR, Northrup H: Tuberous sclerosis complex consensus conference: revised clinical diagnostic criteria. J Child Neurol 1998;13:624-628.

- 3 Sampson JR, Scahill SJ, Stephenson JB, Mann L, Connor JM: Genetic aspects of tuberous sclerosis in the west of Scotland. J Med Genet 1989; 26:28-31.

$\checkmark 4$ Webb DW, Fryer AE, Osborne JP: Morbidity associated with tuberous sclerosis: a population study. Dev Med Child Neurol 1996;38:146155 .
5 Fisher OD, Stevenson AC: Frequency of epiloia in Northern Ireland. Br J Prev Soc Med 1956;10:134-135.

6 6 Devlin LA, Shepherd CH, Crawford H, Morrison PJ: Tuberous sclerosis complex: clinical features, diagnosis, and prevalence within Northern Ireland. Dev Med Child Neurol 2006;48:495-499.

7 Hong CH, Darling TN, Lee CH: Prevalence of tuberous sclerosis complex in Taiwan: a national population-based study. Neuroepidemiology 2009:33:335-341.

8 Lee N, Woodrum CL, Nobil AM, Rauktys AE, Messina MP, Dabora SL: Rapamycin weekly maintenance dosing and the potential efficacy of combination sorafenib plus rapamycin but not atorvastatin or doxycycline in tuberous sclerosis preclinical models. BMC Pharmacol 2009;9:8.

Prof. Patrick J. Morrison

Department of Medical Genetics, A Floor, Belfast HSC Trust, 51

Lisburn Road

Belfast BT9 7AB (UK)

Tel. +44289026 3872, Fax +442890236911

E-Mail patrick.morrison@belfasttrust.hscni.net 